\title{
Procurement management/ material supply on construction projects
}

\author{
Maksum Tanubrata ${ }^{1 *}, I_{k a}$ Gunawan $^{2}$ \\ ${ }^{1}$ Maranatha Christian University, Faculty of Engineering, Department of Civil Engineering, Bandung, Indonesia, \\ ${ }^{2}$ Maranatha Christian University, Faculty of Economics, Department of Management, Bandung, Indonesia
}

\begin{abstract}
Material inventory management is one part of the logistics system devoted to project implementation on material procurement as per the needs plan procurement management is a very important material function, since the material inventory for a construction project involves a considerable investment cost. In general, every construction project involves complex activities, which involves the sharing of activities and operations. Material acquisition activities require good planning and control considering the large percentage of material costs to the total cost of the project. So if less effective material handling will result in loss of time, cost and quality. then this should receive high attention from contractors for the smooth and performance to be achieved in the implementation of construction projects.
\end{abstract}

\section{Introduction}

Material management is intended to support in order to ensure the smooth and efficient implementation of construction projects. The material management objectives include first, buy at a cheap price. Material management aims to buy materials at good and cheap prices. Material management aims to buy materials at a good price. A good price is not always a cheap price in the market. The price is the price that includes discounts and transportation to the project site. Secondly, Product material. Material dating at the right time with the amount and quality that fit with the minimum cost plan. Thirdly, Success delivery Concerning work activities related directly to time and cost. Activities related to those objectives are binding the vendor's efforts to implement on an agreed schedule. Fourthly, Relationships with vendors, good relationships with vendors will provide improved service to contractors. Fifthly, Material storage is an activity to manage inventory of material in a storage area. Material acceptance must conform to the specified order specifications. Sixthly, material use basically the material usage required can be fulfilled in accordance with the time required. Seventhly, material and material quality much happens at the time of delivery of materials by vendors, incompatible with specified specifications and material damage. Then the task of material management to be able to determine the quality of the vendor. Lastly, administration system providing effective and efficient administration logistic services $[1,2]$.

A material management organization on a construction project, completed by a section of the organization that can perform its work according to the required functions in an integrated manner. The shape of the material management organization structure is like the picture below. The duties and responsibilities of each part of the organization are as follows [1]:

1. Practical analysis of material needs (make material requirements analysis) and determine the amount of material inventory.

2. Material ordering section (control the ordering of materials as needed and booking according to frequency based on the number of needs in each period).

3. Material Control and Control Section (report the material state on the purchasing department, prepare the schedule and delivery of materials from the source on the project, supervise the delivery of materials, supervise material compilation and supervise the distribution of materials).

4. The material budget section (record the cost of material expenditure, payment to vendor, and provide a report on the logistics section).

5. Parts of materials warehouse (material acceptance and material distribution)

\section{Procurement Material}

Material inventory is a process of activity where a number of materials are placed in stock to anticipate material needs and market conditions for a certain period so as to ensure the continuity of completion of work activities. A construction project will not run smoothly if it does not use inventory systems and controlled materials to meet the needs. But if the inventory is too large will be detrimental, otherwise if the material inventory is too small also not profitable contractor.

\subsection{Factors affecting material procurement}

\footnotetext{
${ }^{*}$ Corresponding author: maksum.tanubrata150@gmail.com
} 
The main factor factors that influence and materials for a construction project there are several kinds that will be inter-related in the process. The factor is [2-4]:

1. Estimated usage, Prior to material purchases the planning is carried out including the estimated material used including storage as well as ordering in the construction project implementation according to the timetable and the applicable type of work.

2. Determination of expenditure, the amount of material inventory depends on the determination of the amount of expenditure specified in the schedule of material inventory.

3. Lead Time / waiting time, charging time is the time required between material ordering with the arrival of material in order to minimize the cost opportunity loss.

4. The actual material use, information on the characteristics of the results of similar material use from the period may be one of the factors that need attention.

5. Market situation, the condition of a material on the market needs to be considered in the supply of materials, because the completeness of the material in the market is not always appropriate material inventory, because the completeness of the material in the market does not always match the applicable inventory. This situation must be implemented by purchasing materials in large enough quantities but optimum for the project.

6. Economic situation and condition, situations and economic conditions that may affect the targets in the planning that do not specify the needs and disadvantages for the project.

7. Warehousing conditions, wide access and warehouse conditions need to be planned so that it is easy to make acceptance, storage, distribution and administration of material management effective.

\subsection{Procurement arrangements of materials}

Procurement arrangements include:

1. Material selection. Factor factors to consider: (a) Material must not be ordered at a particular vendor without the permission of the consultant planner. (b) All materials must meet the technical requirements of the implementation of work and other technical regulations such as construction regulations, building materials regulations as a reference for planning. (c) The shape, size, placement and installation should be in accordance with the planning and the previous measurement.

2. Material handling Activities include: (a) Material storage. Storage of materials must meet the conditions free of any kind of a damage caused by the accumulation, transportation, demolition of work activities, traffic and security disturbances. (b) Material protection, materials shall be protected from any kind of damage, contamination, staining, discoloration or shape from the time of transportation, lifting, storage, workmanship and installation. (c) Material acceptance, any arrival of material on the field shall be notified to the supervisory consultant, to be subject to prompt review and quality requirements as well as any material must be guaranteed or guaranteed by holding a guarantee or guarantee.

3. Material distribution. The material distribution activity involves moving material from storage to the required material work location with several processes: (a) administration process, (b) information delivery process, (c) expense process, and (d) transportation process

\subsection{Material Cost Control Process}

Material controls meet the accuracy, identification of timeliness and control of all materials required, from design to receipt of materials in the field. Good material control is consistent, comprehensive, and supportive at the time of procurement and during construction. In material management control there are several things to note:

1. Material demand. The material request begins with applying to the purchasing department in case in the owner is required to procure the necessary materials. Reservations must clearly state what is needed to ensure the right materials. Orders must include all information required by the bidder to calculate material costs, such information as: the need for delivery schedules, packing, delivery to the location, transportation used.

2. Check the truth of material acceptance. The material ordered to the supplier, concerning the quantity, variety and quality of the material must be verified. If not suitable or less, then the buyer can return the goods, and the lack of material can be disordered again.

3. Stock control. The function of a stock control is to provide the required goods in quantity of quality in accordance with the time specified by the cost and the most economical way.

4. Storage and material safeguards. Storage control is required to make an estimate of the need the future, where additional stock material information about the state of the material deposited onto the field is entrusted to the shift agent. To reduce high storage costs, materials such as reinforcement are stored outside the warehouse. Material losses can be minimized by setting up sufficient materials of light, the presence of guards or security guards, the location of parkers far enough away from the warehouse. Vehicles and people should not have easy access to the warehouse. Employed employees are employees with good records.

\subsection{Schedule of the preparation}

Schedules is an important factor in construction activity, as it provides an overview of the time-related work required to complete the project. The fault of 
project schedule creation can make project completion longer which impacts the budget spike like overhead cost. There are several things that need to be considered:

1. Schedule covers the entire work. When scheduling, it should first describe the type of work to be done with consideration of the interrelationship between the work of one to another, so it can describe the relationship between the activities and the time required on each work item.

2. Schedule must be an activity and cost. Each project activity to do the work requires a fee, including labor costs, equipment rental fees, and overhead costs.

3. The schedule should be easy to understand and easy to use. Includes plans, drawings or specifications that should be read by more than one person and considered as a prefix for communicating information in a language that is easy to understand. In this case the networking method is used.

\subsection{Networking}

Complete system in preparing network as follows: (1) Identify the project environment and a describe it as component of the activity component. (2) Component activities in the order of dependence logic into network work. (3) Provide the period of each activity. (4) Identify critical path, float, and projects completion period. (5) Improving the usability and utilization of resources.

Networking benefits: (1) Estimate the most economical project schedule. (2) Seek minimal fluctuations in resource use. (3) Complete the sequence of project activities that have a large number of components with complex dependencies. (4) Can find out the length of time estimation of projects completion period

\subsection{Preparation of materials}

A list of materials was created to make it easier for the planner to see the details of the type of material to be used during the construction project. Details consist of:

1. Time or when the material will be used. A description of the time of material use is required so that the executor can estimate when ordering or purchasing a material should be done. It is intended that ordering or purchasing materials is not done too quickly which eventually cause the material buried in the project location because it is not the time to be used or used.

2. The amount of material required for each material. The amount of each material needs is very useful. By knowing the amount of material used, the implementer can estimate the amount of cost required for material procurement.

3. The relevance of the material to the material. The main purpose of this linkage is to enable the executor to know what kind of material to order and what material does not need to be ordered.

\section{Discussion}

\subsection{Material history Requirement Planning (MRP)}

MRP began to be used widely in production management activities since the early 1970s in line with the growing computer and growing with the discovery of various other new concept concepts. This concept first appeared in the manufacturing industry with the characteristics of each period of activity is a process of repetition (representative). Material Requirement Planning (MRP) is a method used to plan the material thoroughly according to the data needs that are influenced by the level of inventory at hand and the acceptance schedule based on the time stages when the material is needed. Data required for Materials Requirement Planning (MRP) method are:

1. Master Schedule (planning a schedule)

2. Bill of material (type, quantity and material specification)

3. Lead time

4. Terms of demand for goods

5. The amount of inventory that still exists.

6. The number of mini8mum items specified.

\subsection{Definition of Material Requirement Planning (MRP)}

According to M. Syamsul Ma'arif et al, in production, MRP is regarded as a life view in manufacturing business management [5]. Besides that, MRP is a system of planning and scheduling of material needs for production that require several stages of the process or in other words production plans for a number of finished products that translated into raw materials needed by using leisure time (lead time) so that can be determined when and how many are ordered for each component of a product made.

The lot for lot a method (LFL) is an approach using the concept on the basis of a discrete ordering with consideration of minimization of the shipping cost, the ordered quantity equals the required amount.

The fixed period requirement (FPR) method is an approach using the concept of a lot of size with a fixed period, where reservations are made a based on a certain period of time. Gross requirement is the requirement of iron material obtained from bill of quantity. The net requirement is the need for gross material reduced by the stock of existing materials.

\subsection{Ability of MRP System}

There are four capabilities that become the main feature of MRP's system:

1. Be able to determine the needs at the right time. The point is to determine precisely, when, a job is 
completed or when material should be available on a planned schedule.

2. Establish minimum requirements on each item. Knowing the need for finished products, material requirement planning (MRP) can precisely determine the scheduling system (based on priority) to meet all minimum requirements of each component item.

3. Determine the implementation of the booking plan. The point is to give an indication of when the booking or cancellation of the booking must be made, either ordering outside or made by yourself.

4. Determine the rescheduling or preparing of a planned schedule.

\section{Conclusion}

Procurement management is urgently needed on a construction project implementation and need for further explanation about procurement / supply of goods by MRP (Material Requirement Planning)

\section{References}

1. A. Sofyan. Production and Operations Management, Rev. edition. (LPFE-UI, Jakarta, 1999)

2. M. Lubis, Development of Prototype Electronic Procurement System (E-procurement) for construction project, master's thesis, Yogyakarta: Islamic University of Bandung. (2006)

3. R, Freddy. Manajemen inventory application in the field of business, management, (PT King Grafindo Persada, Jakarta, 1995).

4. R. Barry, J. Heizer, Principles of operations management. (PT Salemba Emban Patria, Jakarta, 2001)

5. M.S. Ma'arif, H. Tanjung, Manajemen Operasi, (Grasindo, Indonesia, 2003) 